\title{
Oral Cancer: Health Promotion and Visual Screening -A Study Report
}

\author{
Augusta P. Silveiraa, ${ }^{1,2}$, Augusta Marques $^{3}$, Miguel Pavão ${ }^{3}$, Eurico Monteiro ${ }^{1,4}$, Gabriela Pereira ${ }^{1}$, \\ Joaquim Gonçalves ${ }^{1,5}$, Luís Castro ${ }^{1}$, Maria Inês Guimarães ${ }^{1,6}$, Bernardete Carvalho ${ }^{7}$, \\ Cláudia Ribeiro $^{8}$, Teresa Sequeira, ${ }^{1,2 \#}$
}

${ }^{1}$ Faculty of Heath Sciences, Fernando Pessoa University, Porto, Portugal; ${ }^{2}$ Centre of Health Studies and Research, Coimbra University, Coimbra, Portugal; ${ }^{3}$ Non-Governmental Organization (NGO): Mundo A Sorrir, Porto, Portugal; ${ }^{4}$ Portuguese Institute for Oncology, Porto, Portugal; ${ }^{5}$ Instituto Politécnico do Cávado e do Ave, Barcelos, Portugal; ${ }^{6}$ Porto, Portugal; ${ }^{7}$ Well Medical Spa, Porto, Portugal; ${ }^{8}$ Health Sciences Department, Portuguese Catholic University, Viseu, Portugal.

Email: "augusta@ufp.edu.pt, "teresas@ufp.edu.pt

Received July $30^{\text {th }}, 2013$; revised August $28^{\text {th }}, 2013$; accepted September $5^{\text {th }}, 2013$

Copyright (C) 2013 Augusta P. Silveira et al. This is an open access article distributed under the Creative Commons Attribution License, which permits unrestricted use, distribution, and reproduction in any medium, provided the original work is properly cited.

\begin{abstract}
Background: Oral cancer presents a heterogeneous geographic incidence. Annually, more than 275,000 new cases are diagnosed worldwide. In spite of the easy accessibility of oral cavity during physical examination, most malignancies are not diagnosed until late stages of disease. Methods: Oral health promotion was our main objective, risk factors were identified and oral cavity self-examination was promoted. The population considered $(n=1117)$ was divided in two main age groups-a youngest (individuals under 25 years old) mostly targeted for oral cancer awareness and oral cavity self examination promotion, and an older group having accumulated potential risk exposure. Results: The results obtained revealed smoking habits and fruits-vegetables consumption deficit as the highest risks factors found. Considering a Risk Factor Exposure Index analysis, individuals with secondary level of instruction and living in sub-urban areas assumed the highest risk exposure. Alcohol consumption had also contributed as a significant risk exposure. Conclusions: Some of these risk factors work as biological reward of quality of life deficit. A wide comprehension of the problem requires a multidisciplinary approach necessarily involving Health and Social Sciences in order to target the core of oral cancer health promotion. An effective epidemiological strategy must thus support three major aspects: population knowledge, sensitization and visual screening.
\end{abstract}

Keywords: Oral Cancer; Visual Screening; Oral Health Promotion; Epidemiological Strategies

\section{Introduction}

Oral cancer (OC) presents a heterogeneous geographic incidence and reveals to be more frequent in developing countries. Annually, more than 275,000 new cases are diagnosed worldwide-64,000 were identified in European Union (EU) in 2004 [1]. Five percent of all tumors

\footnotetext{
"Competing interests: The author(s) declare that they have no competing interests.

Authors' contributions: AS, MP and TS conceived of study; MP, AS, AM, GP, LC, IG and CR participated in the acquisition of data; JG, AS and TS analysis and interpretation of data; AS and TS drafted, revised and submitted the manuscript; EM was responsible for the instructions and guidelines aimed to scientifically prepare and calibrate the teams involved; JG performed the statistical analysis; BC participated in manuscript elaboration. All authors read and approved the final manuscript.

"Corresponding author.
}

occur in head and neck-such cancers are the $6^{\text {th }}$ common form of cancer in the world and $4^{\text {th }}$ in Europe-approximately half of them occur in oral cavity contributing to an overall of $2.8 \%$ of all cancers [2,3].

Oral cavity includes lips, tongue, oral mucosa, gums, vestibule, mouth floor and palate (ICD9 C00-C06). The most common localizations are mouth floor, tongue lateral edge and soft palate. The five-year survival rate for OC is around $50 \%-60 \%$ [4].

Concerning oral malignancies, squamous cell carcinoma (SCC) contributes with a significant $90 \%$ of such malignancies. It has been recently reported that overall incidence and mortality associated with SCC are increasing, with current estimates of gender-standardized incidence and mortality being 6.6/100,000 and 3.1/ 
100,000 in men and 2.9/100,000 and 1.4/100,000 in women, respectively [5].

As most cases are late diagnosed, therapeutics is either ineffective or physiologically quite aggressive and expensive. When surviving is considered, these patients exhibit a reserved prognosis. Basic physiological functions are often impaired and quality of life of these patients is severely affected [4,6,7].

The decreasing mortality rates in EU (about 7\%) identified since the beginning of the century are not, unfortunately, a world trend: mortality from OC has been rising in several other regions of the world being young people mainly affected $[5,8,9]$.

\subsection{Risk Factors}

Tobacco and alcohol are the main risk factors associated with OC development. Tobacco accounts for the highest share, particularly when non-filter smokers are considered $[8,10]$. It is estimated that 8 out of 10 patients diagnosed with OC consume tobacco or have consumed itthese patients present an increased 5 - 7 fold risk of developing OC when compared with non-smokers. Moreover, the risk of cancer seems to remain elevated many years (at least 10) after smoking cessation [11].

Tobacco and alcohol consumption is associated with approximately $75 \%$ of upper aero digestive tract cancers. Proliferative cells seem to be influenced by alcohol, involving both intracellular (e.g., endocytosis) and intercellular (permeability) pathways [12].

The link of the known risk factors-alcohol and tobacco with oral microorganisms is recently under investigation. It seems that infectious agents interfere both in tumor genesis and defensive factors by causing inflammation with subsequent release of cytokines and other inflammatory mediators, responsible for some oncogenes activation $[13,14]$.

Periodontal disease has also been shown to increase the OC statistic $[15,16]$.

Fruits and vegetables consumption may constitute a protective factor against OC. According to the American Institute for Cancer Research, nutrients such as vitamins and minerals contained contribute to keeping the body healthy and strengthening immune system [17]. Furthermore, phytochemicals, biologically active compounds found in fruits and vegetables, can help protect cells from damages that can lead to cancer. The Mediterranean Diet has been shown to be associated with reduced OC risk [18-21].

Recent OC molecular biology research has also pointed genetic factors as other important risk factors in oral carcinogenesis predisposition [22].

\subsection{Oral Cancer: Visual Screening}

Despite the general accessibility of oral cavity during physical examination, most malignancies concerning this body part are not diagnosed until late stages of disease.

Despite the fact that no clear advantages in OC screening were admitted for decades, several studies point to the obvious advantages associated with visual oral screening $[23,24]$.

\subsection{Oral Cancer: Health Promotion}

Although the increased knowledge and progress made on cancer molecular basis understanding, neither oral cancer incidence nor the 5-year mortality has not decreased in the same proportion [25]. Such facts suggest that challenges remain to explore in OC management: prevention, diagnosis, and surgical and non-surgical treatment. Considering prevention and diagnosis, comprehensive strategies involving the individual at a community level might facilitate integration of the knowledge achievement and population sensitization, needed for decreasing risk factors exposure [26].

\subsection{Aims}

The results of an Oral Health Project for OC prevention are analyzed. Oral health promotion was a main objective of the Project and oral cavity self-examination was promoted. Oral visual screening was performed in order to precociously detect malignant lesions or with malignant transformation potential.

We aimed a further understanding of OC risks factors identified in order to guide more effective future oral health measures.

\section{Methods}

Two main age groups were considered-a youngest population (under 25 years old) mostly targeted for oral cancer awareness and oral cavity self-examination promotion, and an older group having an accumulated risk exposure potential. Socio-demographic, risk exposure and some life style data were collected in order to further understand determinants for OC development.

The Otorhinolaringology service from the Portuguese Institute for Oncology-Porto (IPO-Porto, ORL) performed training actions for dentists and dentistry students' finalists. The instructions and guidelines provided aimed to scientifically prepare and calibrate all 8 dentists' participants and 30 dentistry students' finalists (Dentistry, Msc, Fernando Pessoa University, Porto, Portugal) involved in the screening. Eight work teams were composed with at least 1 dentist and 4 dentistry students.

Each screened individual $(\mathrm{n}=1117)$ was invited to fulfill a questionnaire concerning:

1) Socio-demographic data (gender, age, residency and schooling);

2) Risk factors exposure (tobacco habits, ethylic habits; 
solar radiation; risky profession or risk agents familiarity, fruit and vegetables consumption deficit, family history for OC);

3) Dental health status (oral hygiene; dental prosthesis; parafunctional habits and DMF index-decay/missing/ filled). Concerning oral hygiene, daily brushing times and oral hygiene devices were used to classify as "adequate hygiene level" and "poor hygiene level". It was considered an adequate oral hygiene if: a) brushing was twice a day and took place in the morning after breakfast and at night before sleeping time and $b$ ) hygiene devices used were at least brush, toothbrush and dental floss.

Previous oral infection (Herpes Virus, Human Papiloma Virus or Candida) was not considered for OC risk rating because there was no access to clinical records.

Work teams accomplished 1117 oral visual screenings and held 40 informative sessions concerning OC awareness. About 30 - 40 individuals attended each session that lasted for about 20 minutes. A debate moment followed each session and all questions placed were answered.

All participants resided in Oporto district and voluntarily gave their written informed consent.

This visual oral screening study counted on media divulgation (television, radio, journals and internet). Further, 10,000 informative flyers concerning OC prevention and visual screening, were distributed.

A Risk Factor Exposure Index (RFEI) was designed to express the balance between risk factor exposure and protection. RFEI was calculated based on the number of cigarettes smoked per day, adding 1 point for every 5 cigarettes, the number of years of smoking by adding one point for every 5 years, also adding a point (per item) for drinking alcohol, living with smokers, having parafunctional habits, and excessive sun exposure. The value obtained was subtracted 1 point for each daily meal involving fruit consumption. The measurement was expressed as a percentage.

Student $\mathrm{t}$ test for independent samples was used to investigate risk factors differences when analyzed according to gender, alcohol consumption, and suspected benign lesion. In order to evaluate the differences for risk factor among age groups, years of schooling and residential area, an analysis of variance was performed. The identification of differences between each class of each group was performed by Bonferroni test.

The Statistical Package Social Sciences (SPSS) version 17 for windows, analyzed the collected data.

\section{Results}

All participants $(\mathrm{n}=1117)$ fulfilled the questionnaire and the vast majority of questions (only 67 and 2 missing questions were detected concerning being ex-smokers and having maladjusted dental prosthesis, respectively).

\subsection{Socio-Demographic Characterization}

Major socio-demographic characteristics are depicted in Table 1.

The studied population included both genders in similar numbers (not significant differences) being the majority young (less than 24 years old). A low academic level was a constant: when considering old enough to conclude any education level, it was found that only $27.8 \%(140 /$ 508) concluded the secondary level and a few $4.6 \%$ (15/ 315) concluded University. Individuals were either from urban, sub-urban or rural locations.

\subsection{Risk Exposure}

Major reported risk exposures are depicted in Table 2.

Most individuals declare to be non-smokers $(\mathrm{n}=900)$ and among these $7.8 \%(\mathrm{n}=70)$ admitted to be ex-smokers. Smoking, revealed thus to be one of the most frequent risk behaviors among all others considered. Figure $\mathbf{1}$ characterizes the smoking population considering age and gender.

It was found that youngest group, male individuals (less than 14 years old) smoke significantly more than females. This is indeed the general tendency exception made and inverted when individuals are 25 - 34 years old.

Table 1. Socio-demographic data of the studied population $(n=1117)$.

\begin{tabular}{ccc}
\hline CHEARACTERSTICS & n (\%) \\
\hline Gender & male & $510(45.7)$ \\
Age & female & $601(54.3)$ \\
I & Less than 14 & $614(55.0)$ \\
II & $15-24$ & $188(16.8)$ \\
III & $25-34$ & $66(5.9)$ \\
IV & $35-44$ & $79(7.1)$ \\
V & $45-54$ & $64(5.7)$ \\
VI & $55-64$ & $32(2.9)$ \\
VII & More than 65 & $74(6.6)$ \\
Schooling (years) & & \\
& Basic $(1-9)$ & $962(86.1)$ \\
& Secondary $(10-12)$ & $140(12.5)$ \\
& University $(+13)$ & $15(1.3)$ \\
& & $427(38.2)$ \\
Residential area & Urban & \\
& Sub-urban & \\
& &
\end{tabular}


Table 2. Oral cancer risk exposure distribution found in the studied population $(n=1117)$.

\begin{tabular}{ccc}
\hline RISK EXPOSURE & POSITIVE & NEGATIVE \\
\hline Smokers & 217 & 900 \\
Ex-smokers & 70 & 980 \\
Severe ethylic habits & 78 & 1039 \\
Solar radiation & 239 & 878 \\
Parafunctional habits & 407 & 710 \\
Maladjusted dental prosthesis & 94 & 1021 \\
$\quad \begin{array}{c}\text { Poor oral hygiene } \\
\text { Risky profession or risk } \\
\text { agents familiarity }\end{array}$ & 510 & 607 \\
$\begin{array}{c}\text { Fruit and vegetables } \\
\text { consumption deficit }\end{array}$ & 85 & 1032 \\
Family history for oral cancer & 1083 & 34 \\
\hline
\end{tabular}

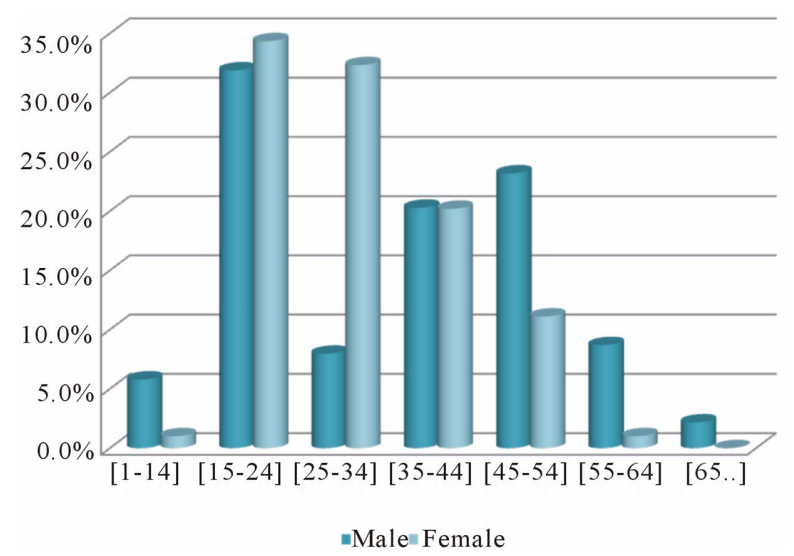

Figure 1. Smokers percentage distribution considering gender and age.

Tobacco consumption revealed to be highest in the 35 54 years old range-later then a decrease is observed, particularly significant in females.

The following figure illustrates daily tobacco exposure (years).

It was observed that tobacco exposure presented two main peaks: 6 - 10 years $(n=36,25$ females and 11 males) and 21 - 30 years $(n=34,11$ females and 23 males). For each period range, exposure is mainly masculine, is similar for periods comprising 3 - 5 years and 16 - 20 years and is mainly feminine both in $6-10$ and 11 - 15 years of exposure. The period of tobacco exposure that included more females was 6 - 10 years $(\mathrm{n}=$ 25).

About thirty eight percent $(n=306)$ of all participants admitted to perform regularly oral self-examination.

The associated Risk Factor Exposure Index (RFEI) found in the studied population is presented in Table 3.
No significant differences were found among genders but when age was considered, several differences were noticed: first, RFEI increases linearly until its peak at age group 45 - 54 years old and than declines at similar levels to those found in the youngest population; second: the age groups 15 - 24 years and 55 - 64 years old assume similar risks being lower than the 25 - 54 years old individuals; third: 35 - 54 years old individuals assume the

Table 3. Risk Factor Exposure Index (RFEI) found in the studied population for the socio-demographic variables (gender, age, schooling years and residency), detected suspected lesions or benign pathology $(n=1117)$.

\begin{tabular}{|c|c|c|}
\hline Characteristics & & RFEI (\%) \\
\hline \multicolumn{3}{|l|}{ Gender } \\
\hline & male & 24.6 \\
\hline & female & 19.4 \\
\hline \multicolumn{3}{|l|}{ Age } \\
\hline I & Less than 14 & 15.1 \\
\hline II & $15-24$ & 23.4 \\
\hline III & $25-34$ & 33.4 \\
\hline IV & $35-44$ & 34.7 \\
\hline V & $45-54$ & 39.4 \\
\hline VI & $55-64$ & 28.7 \\
\hline VII & More than 65 & 15.2 \\
\hline \multicolumn{3}{|l|}{ Schooling (years) } \\
\hline & Basic (1 - 9) & 21.2 \\
\hline & Secondary $(10$ - 12) & 25.3 \\
\hline & University $(+13)$ & 22.8 \\
\hline \multicolumn{3}{|l|}{ Residential area } \\
\hline & Urban & 21.3 \\
\hline & Sub-urban & 24.5 \\
\hline & Rural & 16.7 \\
\hline \multicolumn{3}{|l|}{ Alcohol consumption } \\
\hline & Yes & 39.5 \\
\hline & No & 20.3 \\
\hline \multicolumn{3}{|l|}{ Suspected lesion } \\
\hline & Yes & 24.8 \\
\hline & No & 21.8 \\
\hline \multicolumn{3}{|l|}{ Benign pathology } \\
\hline & Yes & 24.8 \\
\hline & No & 21.8 \\
\hline
\end{tabular}


highest risk exposure.

Considering formal education it was found that individual with secondary level assumed the highest risk exposure, significantly different from other education levels $(\mathrm{p}=0)$.

It was found that rural individuals presented the lower RFEI that revealed to be significantly different from urban $(p=0)$ and sub-urban $(p=0)$. The highest RFEI was found in sub-urban individuals and was significantly different from urban $(p=0.01)$.

Alcohol consumption $(\mathrm{n}=78)$ contributed as a significant higher risk exposure $(p=0)$. Identification of a benign pathology or a suspected lesion, although presented a higher RFEI, differences were not significantthe low number of positive individuals $(n=33$ and $n=15$, respectively) most probably contributed to this circumstance.

During oral visual screening 48 individuals were referred for clinical observation because they presented some oral pathology. Twenty-four lesions with malign transformation potential or suspected malignancy were detected ( $2 \%$ from all screened individuals). After further clinical observation all targeted suspicions were then negatively confirmed.

\section{Discussion}

We found that an important risk factor such as smoking is already present at young ages (less than 14 years old). Tobacco consumption revealed to be highest in the 15 24 years old range and later after a decrease as a whole is observed (Figure 1). This seems to agree with data found in Portugal by Borges and collaborators [27]. Although the across-the-board agreement with anti-smoking measures, along with hope for a reduced general and individual consumption described no changes were detected in the population studied [28].

Alcohol consumption together with tobacco use has been recognized as an important synergistic risk factor for OC for almost 50 years $[29,30]$. The heterogeneous population studied might explain the low percentage of severe ethylic habits found. However, when considering only the older group, the percentage of individuals with severe ethylic habits increased significantly.

The low educational level observed and a significant proportion of individual's exposed to tobacco for quite long periods (Figure 2), supports the need of preventive strategies of oral health promotion, particularly focused among the youngest. Knowledge and attitudes about smoking have been described as varying with sociodemographic characteristics such age, education level and residential area [31-34].

The World Health Organization recommends a consumption of at least $400 \mathrm{~g}$ per day-five servings per day of fruits and vegetables [38], being known that dietary

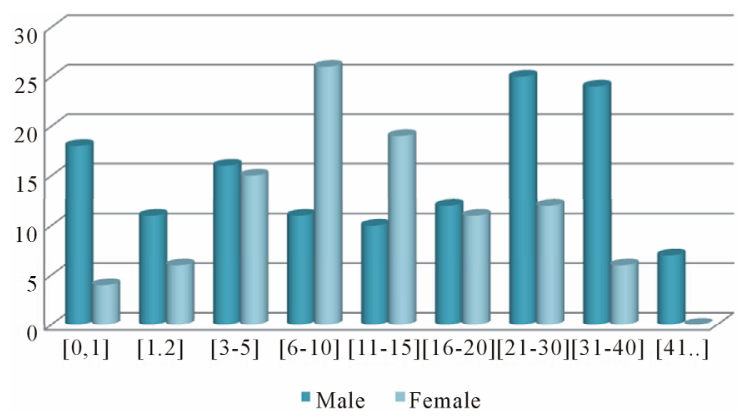

Figure 2. Tobacco exposure (years) considering gender.

deficiencies, especially vitamins $\mathrm{A} / \mathrm{C} / \mathrm{E}$ and iron are considered risk factors [35-37]. Moreover, Petersen (2009) showed that heavy intake of alcoholic beverages is associated with nutrient deficiency, which appears to contribute independently to oral carcinogenesis [38]. Fruits and vegetables consumption deficit reveled to be the highest risk factor in the studied population. This represents a concerning question taking in account the high percentage of young individual and the cumulative effect risk.

Despite the general accessibility of the oral cavity durring physical examination, many malignancies are not diagnosed until late stages of disease [39]. Systematic literature reviews of effectiveness in screening for OC and pre cancer made until early 2000 were found to provide insufficient available data to make an unequivocal determination as to the effectiveness of OC screening programmers at the time [40]. Although OC is almost always preceded by visible changes in the oral mucosa most situations are currently detected at a late stage, when treatment is complex, costly, and has poor outcomes [41].

Sankaranarayanan and collaborators (2005) performed a landmark study when studied a high-risk population in India $(n=96.517)$. They proved for the first time that oral visual inspection was effective in reducing OC mortality. According to their data, visual oral screening was ascribed to a potential of preventing at least 37,000 OC deaths worldwide [23]. More recently, I. How et al. (2011) reported a high sensitivity and specificity (98.9\% and $98.7 \%$, respectively) in an oral cavity visual screening for cancer conducted in a large male population (more then 13,000 men) from a tertiary medical center [42].

The association of the well-known risk factors for oral cancer and its easy detect ability - it is almost always preceded by visible changes in the oral mucosa-converted this disease into a potentially preventable one [25, 41].

However, the diagnostic delay is still a reality-it seems to be assigned by the lack of awareness of the signs, symptoms, and risk factors for OC, as well as a disappointing absence of prevention and early detection 
by health-care providers [41]. Indeed, a recent survey regarding dentists' knowledge of risk factors and diagnostic concepts of OC, Decuseara et al. (2011) found that they appear to be generally knowledgeable regarding diagnostic concepts and risk factors [43]. Nevertheless, these dentists reported a significant lack of patient education regarding prevention and early detection of OC. The fact that economical disadvantaged populations do not visit a dentist regularly further increases its burden risk.

The low educational level found also may account for social needs resulting as a source of non-healthy lifestyles. It is known that both tobacco and alcohol consumption constitute ancient adaptive strategies to overcome unfavorable conditions-such as hunger and coldactivating the dopaminergic reward system [44].

This fact concur to explain why many Public Health measures aimed at preventing OC fail their final goal whenever the eradication of such non-healthy lifestyles is not considered [42].

Our results corroborate others [35] suggesting that it might be possible to improve OC mortality by modifying country-based determinants lifestyles related (not only smoking and drinking prevalence) and improving multidisciplinary approaches prepared by both Social and Health Sciences-it is fundamental a better knowledge for an efficient action.

\section{Conclusions}

The results obtained revealed that smoking habits and fruits-vegetables consumption deficit contributed as the highest risks factors in the studied population. From RFEI analysis, individuals with secondary level and those with sub-urban residential area assumed the highest risk exposure. Alcohol consumption also contributed as a significant higher risk exposure.

Future oral health measures for this group must take in account-tobacco cessation sessions and nutritional reeducation, especially for younger individuals, once these risk factors have a cumulative effect.

Some of these risk factors work as biological reward of quality of life deficit. A wide comprehension of the problem requires a multidisciplinary approach necessarily involving Health and Social Sciences in order to target the core of OC health promotion.

An effective epidemiological strategy must thus support three major aspects: population knowledge, population sensitization and visual screening.

\section{Acknowledgements}

We acknowledge all people who have voluntarily collaborated in the study, all health professionals from the Portuguese Institute of Oncology, Porto, Portugal (IPOPorto) involved and the ORL Service for their generous support. We also acknowledge the Centre of Health
Studies and Research of the University of Coimbra and the Portuguese High Commissioner for Health.

\section{REFERENCES}

[1] S. Warnakulasuriya, "Living with Oral Cancer: Epidemiology with Particular Reference to Prevalence and LifeStyle Changes That Influence Survival,” Oral Oncology, Vol. 46, No. 6, 2010, pp. 407-410. http://dx.doi.org/10.1016/j.oraloncology.2010.02.015

[2] D. M. Saman, "A Review of the Epidemiology of Oral and Pharyngeal Carcinoma: Update,” Head \& Neck Oncology, Vol. 4, No. 1, 2012, p. 1.

[3] D. Kademani, “Oral Cancer,” Mayo Clinic Proceedings, Vol. 82, No. 7, 2007, pp. 878-887. http://dx.doi.org/10.4065/82.7.878

[4] A. Zini, R. Czerninski and H. D. Sgan-Cohen, “Oral Cancer over Four Decades: Epidemiology, Trends, Histology, and Survival by Anatomical Sites," Journal of Oral Pathology \& Medicine, Vol. 39, No. 4, 2010, pp. 299-305. http://dx.doi.org/10.1111/j.1600-0714.2009.00845.x

[5] P. Sharma, S. Saxena and P. Aggarwal, "Trends in the Epidemiology of Oral Squamous Cell Carcinoma in Western UP: An Institutional Study,” Indian Journal of Dental Research, Vol. 21, No. 3, 2010, pp. 316-319. http://dx.doi.org/10.4103/0970-9290.70782

[6] B. Y. Goldstein, S-C. Chang, M. Hashibe, C. La Vecchia and Z-F. Zhang, "Alcohol Consumption and Cancer of the Oral Cavity and Pharynx from 1988 to 2009: An Update,” European Journal of Cancer Prevention, Vol. 19, No. 6, 2010, pp. 431-465.

http://dx.doi.org/10.1097/CEJ.0b013e32833d936d

[7] M. Gorsky, J. B. Epstein, C. Oakley, N. D. Le, J. Hay and P. Stevenson-Moore, "Carcinoma of the Tongue: A Case Series Analysis of Clinical Presentation, Risk Factors, Staging, and Outcome," Oral Surgery, Oral Medicine, Oral Pathology, Oral Radiology and Endodontology, Vol. 98, No. 5, 2004, pp. 546-552.

http://dx.doi.org/10.1016/j.tripleo.2003.12.041

[8] M. Bonifazi, M. Malvezzi, P. Bertuccio, et al., “AgePeriod-Cohort Analysis of Oral Cancer Mortality in Europe: The End of an Epidemic?” Oral Oncology, Vol. 47, No. 5, 2011, pp. 400-407.

http://dx.doi.org/10.1016/j.oraloncology.2010.06.010

[9] T. Rodriguez, A. Altieri, L. Chatenoud, et al., "Risk Factors for Oral and Pharyngeal Cancer in Young Adults," Oral Oncology, Vol. 40, No. 2, 2004, pp. 207-213. http://dx.doi.org/10.1016/j.oraloncology.2003.08.014

[10] G. C. Kabat, C. J. Chang and E. L. Wynder, "The Role of Tobacco, Alcohol Use, and Body Mass Index in Oral and Pharyngeal Cancer,” International Journal of Epidemiology, Vol. 23, No. 6, 1994, pp. 1137-1144. http://dx.doi.org/10.1093/ije/23.6.1137

[11] C. Bosetti, S. Gallus, W. Garavello and C. La Vecchia, "Smoking Cessation and the Risk of Oesophageal Cancer: An Overview of Published Studies," Oral Oncology, Vol. 42, No. 10, 2006, pp. 957-964.

http://dx.doi.org/10.1016/j.oraloncology.2006.03.007 
[12] S. Petti and C. Scully, "Oral Cancer: The Association between Nation-Based Alcohol-Drinking Profiles and Oral Cancer Mortality,” Oral Oncology, Vol. 41, No. 8, 2005, pp. 828-834.

http://dx.doi.org/10.1016/j.oraloncology.2005.04.004

[13] J. H. Meurman, "Infectious and Dietary Risk Factors of Oral Cancer,” Oral Oncology, Vol. 46, No. 6, 2010, pp. 411-413. http://dx.doi.org/10.1016/j.oraloncology.2010.03.003

[14] J. H. Meurman and J. Uittamo, "Oral Micro-Organisms in the Etiology of Cancer,” Acta Odontologica Scandinavica, Vol. 66, No. 6, 2008, pp. 321-326. http://dx.doi.org/10.1080/00016350802446527

[15] S. G. Fitzpatrick and J. Katz, "The Association between Periodontal Disease and Cancer: A Review of the Literature,” Journal of Dentistry, Vol. 38, No. 2, 2010, pp. 8395. http://dx.doi.org/10.1016/j.jdent.2009.10.007

[16] Z. Nugent, "Periodontal Disease May Be Associated with Oral and Gastrointestinal Cancer," Journal of Evidence Based Dental Practice, Vol. 10, No. 4, 2010, pp. 223-224. http://dx.doi.org/10.1016/j.jebdp.2010.09.012

[17] American Institute for Cancer Research, "World Cancer Research Fund: Food, Nutrition, Physical Activity, and the Prevention of Cancer: A Global Perspective,” AICR, Washington DC, 2007.

[18] S. C. Chuang, M. Jenab, J. E. Heck, et al., "Diet and the Risk of Head and Neck Cancer: A Pooled Analysis in the INHANCE Consortium," Cancer Causes Control, Vol. 23, No. 1, 2012, pp. 69-88. http://dx.doi.org/10.1007/s10552-011-9857-x

[19] P. Latino-Martel, N. Druesne-Pecollo and A. Dumond, "Nutritional Factors and Oral Cancers," Revue de Stomatologie et de Chirurgie Maxillo-Faciale, Vol. 112, No. 3, 2011, pp. 155-159. http://dx.doi.org/10.1016/j.stomax.2011.04.002

[20] E. Lucenteforte, W. Garavello, C. Bosetti and C. La Vecchia, "Dietary Factors and Oral and Pharyngeal Cancer Risk,” Oral Oncology, Vol. 45, No. 6, 2009, pp. 461-467. http://dx.doi.org/10.1016/j.oraloncology.2008.09.002

[21] M. Paiva, C. Pileggi, C. Nobile and I. Angelillo, “Association between Fruit and Vegetable Consumption and Oral Cancer: A Meta-Analysis of Observational Studies,” American Journal of Clinical Nutrition, Vol. 83, 2006, pp. 1126-1134.

[22] X. Marichalar-Mendia, M. J. Rodriguez-Tojo, A. AchaSagredo, N. Rey-Barja and J. M. Aguirre-Urizar, "Oral Cancer and Polymorphism of Ethanol Metabolising Genes,” Oral Oncology, Vol. 46, No. 1, 2010, pp. 9-13. http://dx.doi.org/10.1016/j.oraloncology.2009.09.005

[23] R. Sankaranarayanan, K. Ramadas, G. Thomas, et al., "Effect of Screening on Oral Cancer Mortality in Kerala, India: A Cluster-Randomised Controlled Trial,” The Lancet, Vol. 365, No. 9475, 2005, pp. 1927-1933. http://dx.doi.org/10.1016/S0140-6736(05)66658-5

[24] K. Ramadas, S. Arrossi, S. Thara, et al., "Which SocioDemographic Factors Are Associated with Participation in Oral Cancer Screening in the Developing World? Results from a Population-Based Screening Project in India," Cancer Detection and Prevention, Vol. 32, No. 2,
2008, pp. 109-115.

http://dx.doi.org/10.1016/j.cdp.2008.02.008

[25] K. J. Elango, N. Anandkrishnan, A. Suresh, S. K. Iyer, S. K. RamaIyer and M. A. Kuriakose, "Mouth Self-Examination to Improve Oral Cancer Awareness and Early Detection in a High-Risk Population," Oral Oncology, Vol. 47, No. 7, 2011, pp. 620-624. http://dx.doi.org/10.1016/j.oraloncology.2011.05.001

[26] L. Calabrese, A. Ostuni, M. Ansarin, G. Giugliano, F. Maffini, D. Alterio, M. C. Rocca, G. Petralia, R. Bruschini and F. Chiesa, "On Behalf of AROME: Future Challenges in Head and Neck Cancer: From the Bench to the Bedside?" Critical Reviews in Oncology/Hematology, Vol. 84, No. 1, 2012, pp. e90-e96. http://dx.doi.org/10.1016/j.critrevonc.2010.11.001

[27] A. Borges, F. Marques, J. Lima, et al., "Smoking Habits of Sixth Year Medical Students and Anti-Smoking Measures in Portugal," Revista Portuguesa de Pneumologia (English Edition), Vol. 14, No. 3, 2008, pp. 379-390.

[28] A. Borges, F. Marques, J. Lima, et al., "Smoking Habits of Sixth Year Medical Students and Anti-Smoking Measures in Portugal,” Revista Portuguesa de Pneumologia (English Edition), Vol. 14, No. 2, 2008, pp. 219-230.

[29] S. Petti and C. Scully, "Determinants of Oral Cancer at the National Level: Just A Question of Smoking and Alcohol Drinking Prevalence?” Odontology, Vol. 98, No. 2, 2010, pp. 144-152. http://dx.doi.org/10.1007/s10266-010-0133-4

[30] A. Silveira, J. Gonçalves, T. Sequeira, et al., "Head and Neck Cancer: Health Related Quality of Life Assessment Considering Clinical and Epidemiological Perspectives," Revista Brasileira de Epidemiologia, Vol. 15, No. 1, 2012, pp. 38-48.

http://dx.doi.org/10.1590/S1415-790X2012000100004

[31] A. Silveira, J. Gonçalves, T. Sequeira, et al., "Geriatric Oncology: Comparing Health Related Quality of Life in Head and Neck Cancer Patients," Head \& Neck Oncology, Vol. 3, 2011, p. 3.

[32] L.-S. Lin, D.-M. Wu, H.-R. Lai, Z.-P. Shi and N.-F. Chu, "Influence of Knowledge and Attitudes on Smoking Habits Among Young Military Conscripts in Taiwan,” Journal of the Chinese Medical Association, Vol. 73, No. 8, 2010, pp. 411-418.

http://dx.doi.org/10.1016/S1726-4901(10)70089-7

[33] L. Clancy, "Progress in Tobacco Control," Health Policy, Vol. 91, No. 1, 2009, pp. S3-S14. http://dx.doi.org/10.1016/S0168-8510(09)70003-X

[34] R. M. John, “Tobacco Consumption Patterns and Its Health Implications in India,” Health Policy, Vol. 71, No. 2, 2005, pp. 213-222. http://dx.doi.org/10.1016/j.healthpol.2004.08.008

[35] B. N. Ames, "DNA Damage from Micronutrient Deficiencies Is Likely to Be a Major Cause of Cancer," Mutation Research/Fundamental and Molecular Mechanisms of Mutagenesis, Vol. 475, No. 1-2, 2001, pp. 7-20.

[36] World Health Organization, "Diet, Nutrition and the Prevention of Chronic Diseases: Report of a Joint WHO/ FAO Expert Consultation,” 2003.

[37] C. F. Garland, E. D. Gorham, S. B. Mohr and F. C. Gar- 
land, "Vitamin D for Cancer Prevention: Global Perspective,” Annals of Epidemiology, Vol. 19, No. 7, 2009, pp. 468-483.

http://dx.doi.org/10.1016/j.annepidem.2009.03.021

[38] P. E. Peterson, "Oral Cancer Prevention and ControlThe Approach of the World Health Organization,” Oral Oncology, Vol. 45, No. 4-5, 2009, pp. 454-460. http://dx.doi.org/10.1016/j.oraloncology.2008.05.023

[39] T. O. Steele and A. Meyers, "Early Detection of Premalignant Lesions and Oral Cancer," Otolaryngologic Clinics of North America, Vol. 44, No. 1, 2011, pp. 221-229. http://dx.doi.org/10.1016/j.otc.2010.10.002

[40] L. L. Patton, "The Effectiveness of Community-Based Visual Screening and Utility of Adjunctive Diagnostic Aids in the Early Detection of Oral Cancer," Oral Oncology, Vol. 39, No. 7, 2003, pp. 708-723. http://dx.doi.org/10.1016/S1368-8375(03)00083-6
[41] M. D. Mignogna and S. Fedele, "Oral Cancer Screening: 5 Minutes to Save a Life,” The Lancet, Vol. 365, No. 410, 2005, pp. 1905-1906.

[42] C.-I. How, R.-S. Jiang, Y.-K. Wong, S.-H. Wu, F.-J. Chen and S.-A. Liu, "Visual Screening of Oral Cavity Cancer in a Male Population: Experience from a Medical Center," Journal of the Chinese Medical Association, Vol. 74, No. 12, 2011, pp. 561-566. http://dx.doi.org/10.1016/j.jcma.2011.09.014

[43] G. Decuseara, D. MacCarthy and G. Menezes, “Oral Cancer: Knowledge, Practices and Opinions of Dentists in Ireland,” Journal of the Irish Dental Association, Vol. 57, No. 4, 2011, pp. 209-214.

[44] S. Petti, "Review: Lifestyle Risk Factors for Oral Cancer,” Oral Oncology, Vol. 45, No. 4, 2009, pp. 340-350. http://dx.doi.org/10.1016/j.oraloncology.2008.05.018 